\title{
$\mathrm{C}^{-} \mathrm{I}$ CONGRESO \\ INTERNACIONAL \\ SOBRE \\ FOTOGRAFÍA
}

Congreso Internacional sobre Fotografía

UPV, 5 y 6 octubre 2017

Doi:http://dx.doi.org/10.4995/CIFo17.2017.6748

ISBN: 978-84-9048-604-7

\section{"RELATOS DEL YO": autobiografías visuales, foto de familia y autorretrato fotográfico como recursos de autoconocimiento en jóvenes y adultos con NEE".} Graciela López Camarán. gracielalopezc@gmail.com

\begin{abstract}
This is a feasible project carried out via a photography workshop with self-portraiture, visual autobiography and family photos used as self-knowledge resources for people with SEN. Qualitative research with a population of 14 young people and adults displaying different characteristics: autism, Down syndrome, Aspergers, Prader Willi, moderate and slight mental retardation among others. Techniques: documentary evidence, observation, and summative pre-test and post-test assessment. The results show that: photography helps to activate high-level processes linked to the act of reading and writing; it aids the development of different kinds of intelligence; the self-portrait mode serves a method for projecting, constructing and reconstructing one's own identity. Family albums and family photos are both an excellent means of narration, as they directly involve the person in what is narrated. The interactive process of inference and connotation was carried out through the construction of the autobiographic narrative. These resources immerse the individual in their subjective world and help to consolidate their identity via their vital reality. Photographic images are an effective tool for encouraging proper self-appraisal, self-knowledge and self-esteem.
\end{abstract}

Keywords: Photography, visual autobiography, photographic self-portrait, family photo, special educational needs.

\begin{abstract}
Resumen
Se trata de un proyecto factible desarrollado a través de un taller de fotografía de autorretrato, autobiografía visual y foto de familia, utilizados como recursos de autoconocimiento en personas con NEE. Una investigación cualitativa, con una población de 14 jóvenes y adultos con características diversas: autismo, sindrome de Asperger, Down, Prader Willi, retraso mental moderado y ligero, entre otros. Técnicas: documental, observación y evaluación pretest-postest sumativa. Los resultados concluyen que: la fotografía ayuda a activar procesos de alto nivel relacionados con el acto de leer y escribir; contribuye al desarrollo de los diferentes tipos de inteligencias; en su faceta de autorretrato, sirve de método proyectivo y de construcción y reconstrucción de la identidad propia. Tanto el álbum familiar como la foto de familia son un medio privilegiado de narración, puesto que involucran a la persona directamente con lo narrado. A través de la construcción del relato visual autobiográfico, se llevó a cabo el proceso interactivo, de inferencia y de connotación. Dichos recursos sumergen al individuo en su mundo subjetivo, ayudando a cimentar su identidad por medio de su realidad vital. La imagen fotográfica es una herramienta eficaz para favorecer la adecuada valoración personal, el autoconocimiento y la autoestima.
\end{abstract}

Palabras claves: fotografía, autobiografía visual, autorretrato fotográfico, foto de familia, necesidades educativas especiales. 
"Relatos del YO": autobiografias visuales, foto de familia y autorretrato fotográfico como recursos de autoconocimiento en jóvenes y adultos con NEE

\section{Introducción.}

“Pienso donde no soy, luego soy donde no pienso”. (Lacan, J. P:484). ${ }^{1}$ El conocimiento es construido por la actividad del hombre en relación con los otros yo. Es a partir de las relaciones de comunicación con los otros que se establece el diálogo, la comprensión y la apertura a otras formas de vida, culturas, sociedades o realidades diversas; en este concepto se basa la tolerancia, el pluralismo razonable y el reconocimiento al otro del derecho a la diferencia. Es por y a través de esta facultad innata de intercambio social que el niño, desde el momento de su nacimiento, busca la comprensión del medio que lo rodea a través de los distintos tipos de percepción, para posteriormente interpretar o imitar reproduciendo formas, expresiones y/o situaciones cotidianas. En la medida que va avanzando su edad, establece lazos comunicativos y de relaciones con los otros para lo cual toma los elementos que considera importantes para su entendimiento, organizándolos armoniosamente (Vera, B. 2000) ${ }^{2}$ con el fin de proyectar las situaciones vivenciales que expresan sus relaciones con lo social. Como factor productor de la comunicación se encuentra la creatividad. Las personas creativas utilizan de forma constante la intuición y se interesan en el pensamiento abstracto y subjetivo de su mundo interior en relación con los otros y

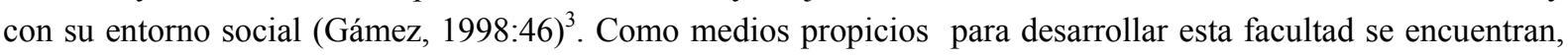
entre otros, las artes visuales en sus distintas manifestaciones, las cuales favorecen el desarrollo de la capacidad de expresión de cualquier individuo, permitiendo de esta manera una adecuada comunicación consigo mismo, con los otros y con el mundo en general.

Esta investigación trata sobre cómo la fotografía en su estado de autorretrato fotográfico, autobiografía visual o en su forma de archivo como lo es la foto o el álbum de familia, se puede utilizar como recurso de autoconocimiento por individuos con necesidades educativas especiales como vehículos comunicacionales para la creación de su propio relato de vida, contribuyendo a tomar conciencia de su persona creando una correcta percepción de sí mismos y una valoración y construcción adecuada de su identidad, al tiempo que favorece el autoconocimiento, la autoconsciencia y la autoestima; acciones que ayudarán a integrarse de manera adecuada a sus capacidades en la sociedad de la cual forman parte.

\section{Objetivo General de la Investigación:}

El objetivo general de la presente investigación es el estudio de la utilización de la autobiografía y el autorretrato fotográfico, así como la foto de familia y los álbumes familiares como recursos para favorecer el autoconocimiento, la auto-conciencia, un autoconcepto ajustado y niveles adecuados de autoestima, facilitando la expresión y el desarrollo personal en jóvenes y adultos con NEE.

\subsection{Objetivos Específicos de la investigación.}

Conocer la normativa que regula las actuaciones relacionadas con el alumnado que presenta necesidades educativas especiales.

--Conocer las principales características y necesidades educativas en jóvenes y adultos con NEE para diseñar una programación por proyectos enfocada a la diversidad.

\footnotetext{
${ }^{1}$ LACAN, J. La instancia de la letra en el inconsciente o la razón desde Freud 2013. P: 484

${ }^{2}$ VERA, B. El arte: factor determinante en el proceso educativo. 2000. P: 56-65.

${ }^{3}$ GÁMEZ, G. Todos somos creativos, Barcelona, Urano. 1998. P:46.
} 
,-Establecer una aproximación teórica que, de manera sencilla, analice el papel del autorretrato fotográfico y la escritura autobiográfica así como la foto de familia como recursos para la mejora del autoconocimiento, la autoconciencia, el autoconcepto y la autoestima en jóvenes y adultos con NEE.

--Diseñar e impartir un taller de autorretrato fotográfico y autobiografía para jóvenes y adultos con necesidades educativas espaciales.

--Analizar y organizar los resultados del taller.

-Identificar los factores del taller que tienen mayor impacto en el desarrollo del autoconocimiento y autoconciencia en personas con NEE.

\section{Desarrollo de la innovación.}

\subsection{Metodología de la investigación.}

Consiste en una investigación de carácter cualitativo, diseñada bajo la tipología de proyecto factible. Organizada en cinco capítulos: en el primero, se desarrolló el planteamiento del problema; el segundo, se refiere al marco teórico que sustentó la investigación: la definición y conceptualización de la atención a la diversidad, las bases legales que sustentan la actuación hacia la diversidad en España y una aproximación a la definición de los conceptos de autorretrato fotográfico, autobiografías visuales, así como de álbum y foto de familia; en el tercer capítulo, se presentó la metodología utilizada para la recolección de la información; en el cuarto, se realizó el diseño de un taller de fotografía autobiográfica por medio del análisis y estudio comparado de la información teórica recabada sobre las distintas temáticas tratadas; en el tercer momento de la investigación se efectuó una ejecución experimental del taller de fotografía, autorretrato y autobiografía en la Fundación Down Zaragoza; y en el quinto se expusieron los resultados y las conclusiones.

\subsection{Instrumentos de recolección de datos y de evaluación.}

Para la recopilación de la información, se recurrió a la técnica documental y la técnica de observación directa. Para la evaluación del proyecto, se utilizaron varios métodos: el primero es una evaluación pretest-postest sumativa a través de un cuestionario de preguntas por medio de la escala de autoestima Rosemberg ${ }^{4}$, a fin de analizar el efecto que el taller ha producido en los participantes y de esa forma evaluar el nivel de autoestima de los mismos. Se diseñó un instrumento en forma de mapa mental del proyecto de vida individual antes y otro después del taller para observar los cambios de manera cualitativa. Para la recolección de información general se realizó la técnica de observación directa a través de un registro de anécdotas diarias. Otros instrumentos de recolección de datos fueron los trabajos efectuados por los participantes, que incluyen los relatos autobiográficos, los relatos fotográficos y las fotografías de autorretrato.

\footnotetext{
${ }^{4}$ Cuestionario para explorar la autoestima personal entendida como los sentimientos de valía personal y de respeto a sí mismo: Ítems 1 al 5, las respuestas A a D se puntúan de 4 a 1. Ítems del 6 al 10. las respuestas A a D de 1 a 4.
} 
"Relatos del YO”: autobiografías visuales, foto de familia y autorretrato fotográfico como recursos de autoconocimiento en jóvenes y adultos con NEE

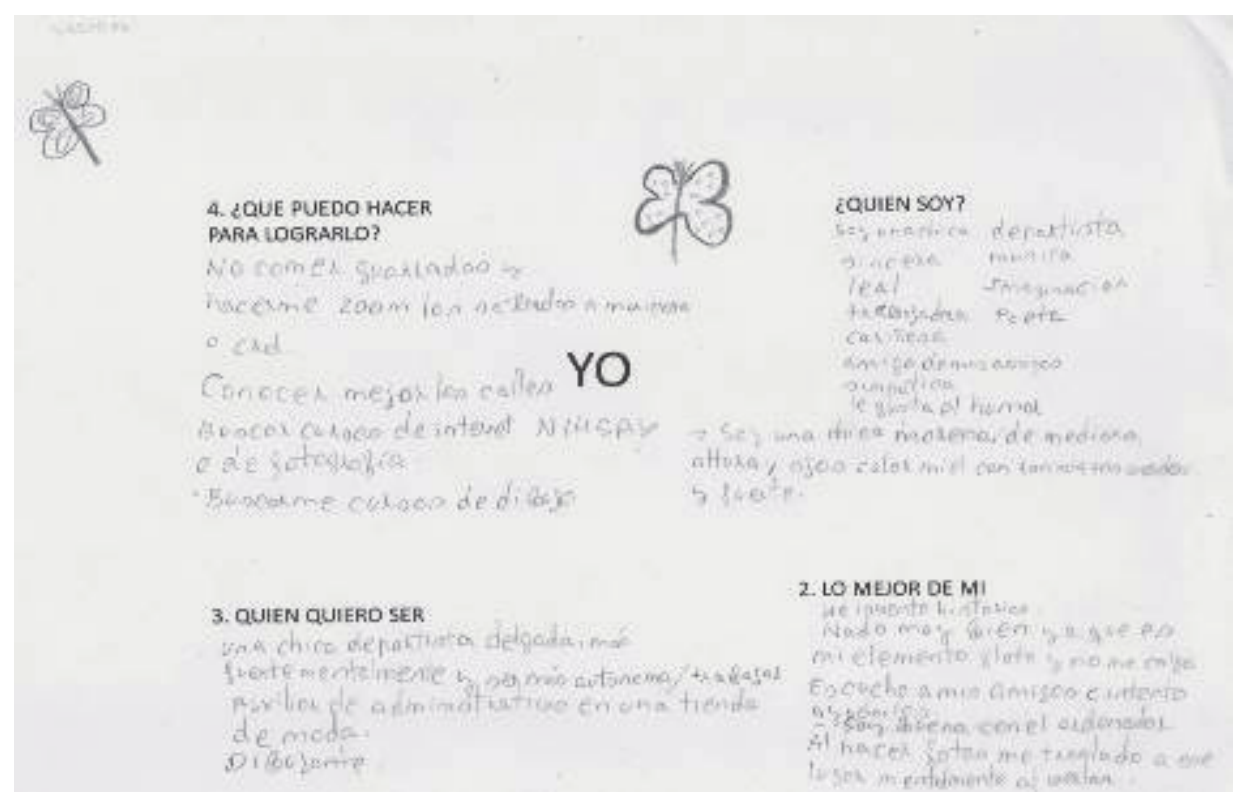

Figura 1: mapa mental del proyecto de vida

3.3. Descripción del proyecto: La intervención se realizó en la Fundación Down Zaragoza en el año 2013. La población del taller estuvo constituida por los asistentes regulares a los talleres de adultos de dicha fundación. Son 14 personas con edades comprendidas entre 22 y 32 años, con características muy diversas: Autismo, síndrome de Asperger, síndrome de Down, síndrome de Prader Willi, retraso mental moderado, retraso mental ligero, inteligencia límite, discapacidad del sistema neuromuscular, enfermedad del aparato circulatorio y discapacidad intelectual por tumor cerebral.

Fue diseñado bajo el esquema de proyectos de aprendizaje, enfocándose en el trabajo en grupo y el cooperativismo. Consta de 14 actividades relacionadas entre sí, que a su vez forman parte de una totalidad, resultando en un álbum autobiográfico construido por medio del autorretrato fotográfico y la autobiografía.

La razón principal del proyecto consistió en lograr que el individuo fuera protagonista de su propio aprendizaje, en el que se le brindaran las herramientas para poder autoexplorarse, hablar a través del lenguaje fotográfico, reconocerse y construir su propio relato en comunicación con otros individuos y con su entorno social, acción que les permitió en la mayoría de los casos tomar conciencia de su persona, planteando o llevando a la palestra situaciones personales que, vistas desde ese otro ángulo, les permitieron darse cuenta de ellas.

Por esta razón se insistió en incluir los tres procesos comunicacionales -el de la lectura, la escritura y la oralidadde manera conjunta tanto a nivel micro como a nivel macro en todo el proyecto, entendiendo la lectura como el proceso de producción de sentido y corrección de los textos visuales y/o escritos por ellos y sus compañeros, con el fin de obtener la consolidación del proceso de la organización del código literario y/o fotográfico para, de esta forma, emitir un mensaje coherente y cohesionado. Estos dos procesos se combinan con la oralidad que es vista como elemento de suma importancia para lograr la adecuación de lo escrito, así como la expresión de lo sentido.

3.4. Objetivo General del taller: Desarrollar la capacidad de representar de forma personal y creativa distintos aspectos que pertenecen al orden de la realidad, lo simbólico y/o imaginario ${ }^{5}$ de su vida y expresarlos a través

\footnotetext{
${ }^{5}$ En este caso se habla de realidades, ya que lo "real" "se trata de lo que no es imaginario ni se puede simbolizar". Lo real es no-representable. Mientras la "realidad", pertenece al orden del lenguaje. LACAN, J (1953). "SIR, lo simbólico, lo imaginario y lo real". 1953.
} 
del autorretrato fotográfico y la autobiografía. Fortalecer el autoconocimiento y la autoestima de los jóvenes y adultos, a partir de su experiencia en el proyecto. Promover una persona con capacidad de autocritica, capaz de construir su propio conocimiento por medio de la auto-organización y la autogestión. Brindarles herramientas para que, a través de las artes visuales puedan autoexplorarse, hablar a través del lenguaje fotográfico, reconocerse y construir el relato de sus visiones sobre sí mismos en comunicación con otros individuos y con su entorno social.

3.5. Objetivo pedagógico: Diseñar una metodología aplicable que desarrolle procesos cognitivos que les permitan construir el conocimiento de sí mismo, basado en experiencias significativas. Para consolidar habilidades, realizar análisis críticos y analogías entre diferentes situaciones vitales previas o actuales aplicando el razonamiento y la toma de decisiones a fin de enfrentar realidades o dificultades de su vida cotidiana.

3.6. Objetivos actitudinales: Potenciar la empatía y el desarrollo emocional, reforzar la autoestima y las habilidades sociales; Reestructuración cognitiva en relación con la identidad personal; Aprendizaje de habilidades sociales con énfasis conducta asertiva.

3.7. Teorías pedagógicas; La planificación y estrategias pedagógicas estuvieron orientadas bajo la metodología de aprendizaje significativo, constructivismo y de acción participativa. Su propósito es el de resolver problemas a través del proceso de enseñanza-aprendizaje significativo, tratando de hacer comprensible el mundo social y buscar mejorar la calidad de vida de las personas. Enfoque de representación holística Kaufman. Enfoque constructivista del aprendizaje sociocultural Vigostky. Escuela Serena Cossettini. Pensamiento crítico y educación problematizadora Freire. Diseño dialéctico y crítico Grundy. 8 inteligencias Gardner. Los pilares de la educación de Jackes Delors (1996): Aprender a conocer, Aprender a hacer, Aprender a vivir juntos, Aprender a ser.

3.8. Contenidos: El taller se estructura en una serie de actividades relacionas entre sí. Entre ellas, se diferencian trabajos de tipo individual y de grupo. En cada sesión se plantea hacer una tarea concreta, previamente planificada, que es consecuencia de las anteriores, permitiendo el aprendizaje bucleico. Los jóvenes hacen lo que está previsto dejando espacio para la improvisación creativa individual. Cada actividad cuenta con un área de actuación y objetivos propios, sin embargo, dichas actividades micro se encuentran encuadradas dentro de un macro proyecto final que será la realización de un álbum autobiográfico. La temática principal a abordar será la autobiografía y el autorretrato, partiendo de la afirmación de que toda creación literaria, fotográfica, audiovisual, plástica o musical, es una autobiografía, un relato de la vida de ese artista. La clase o actividad estará bien estructurada, con momentos de inicio o motivación, desarrollo y cierre claramente establecidos. Tomando en cuenta las características personales de cada uno de los jóvenes y estableciendo estrategias tanto de trabajo individual como grupal. La mayoría estuvieron basadas en la obra de un artista que se estudió previamente. Los fotógrafos que se utilizaron como base temática fueron: Cindy Sherman, Jen Davis, Franck Juery, Martin Parr, Carma Casulá, Jim Golbedg, Richard Billingham, Shopie Calle. Los objetivos actitudinales se vertieron en unos contenidos procedimentales que buscaban la expresión del Yo. 
"Relatos del YO”: autobiografías visuales, foto de familia y autorretrato fotográfico como recursos de autoconocimiento en jóvenes y adultos con NEE

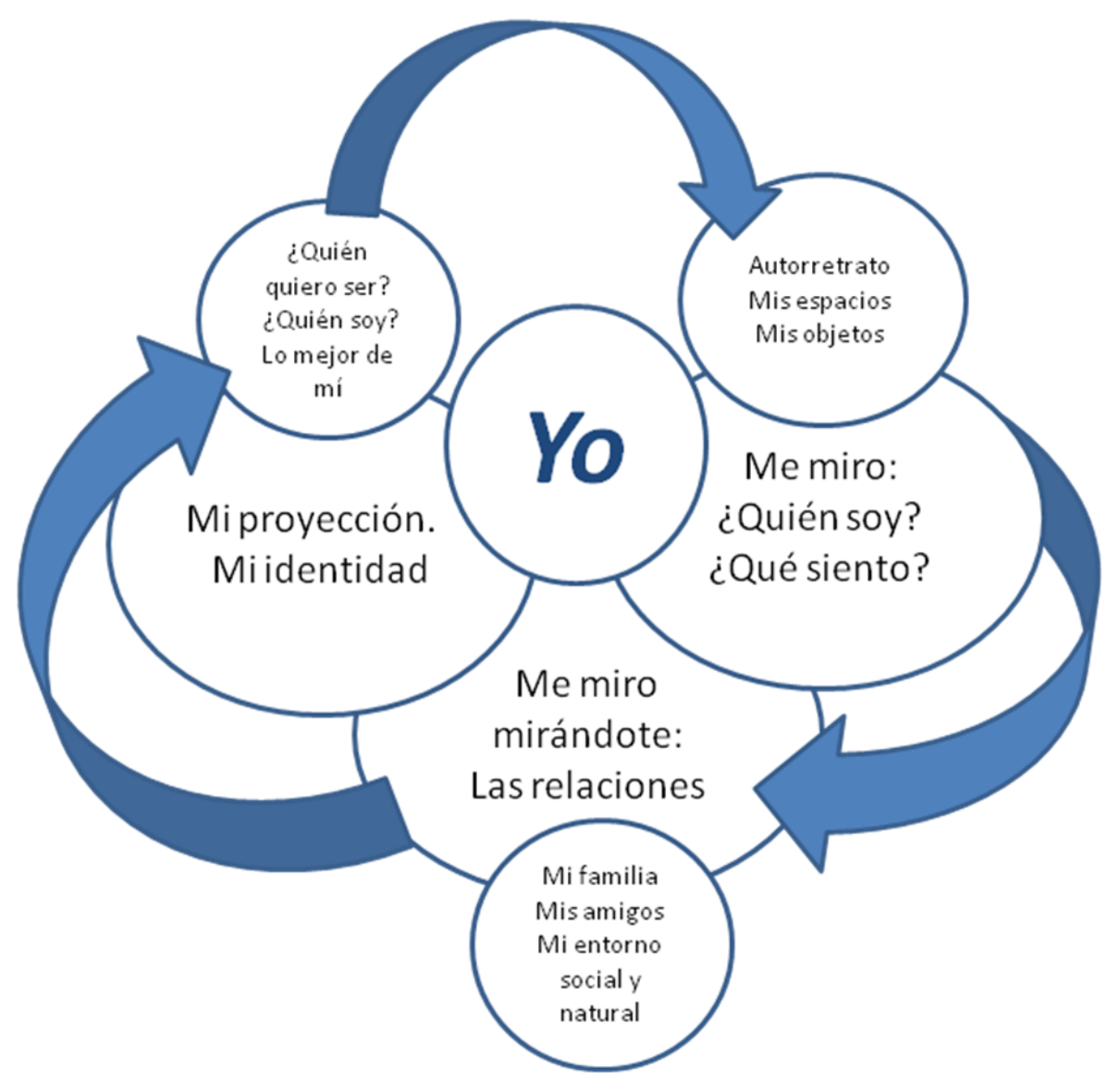

Figura 2: Red de contenidos actitudinales (función expresiva del Yo).

Tabla 1: Estructura del proyecto en cuanto a los contenidos actitudinales (funciones expresiva del Yo).

\begin{tabular}{|l|l|l|}
\hline $\begin{array}{l}\text { TEMA I. } \\
\text { Me miro: ¿Quién soy? ¿Qué siento? }\end{array}$ & $\begin{array}{l}\text { TEMA II. } \\
\text { Me miro mirándote: Las relaciones. }\end{array}$ & $\begin{array}{l}\text { TEMA III. } \\
\text { Mi proyección. }\end{array}$ \\
\hline $\begin{array}{l}\text { Autorretrato. Mis espacios } \\
\text { Mis objetos. }\end{array}$ & $\begin{array}{l}\text { Mi familia. Mis amigos. } \\
\text { Mi entorno social y natural. }\end{array}$ & $\begin{array}{l}\text { ¿quén quiero ser?. } \\
\text { Lo mejor de mí. }\end{array}$ \\
\hline
\end{tabular}

3.9. Posibles aplicaciones en otras áreas. Dicho estudio metodológico se puede aplicar en otras áreas, tales como: Terápia con mujeres y niñas víctimas de la violencia, o usado en el área educativa en casos de bulliyng o acoso escolar, así como en todas las áreas en las que sea necesario la exaltación y liberación del Yo, el aumento de la autoestima y la reestructuración de la identidad.

\section{Resultados.}

El diseño de la intervención, que incluye los objetivos, los contenidos, los recursos así como los procedimientos, la escogencia del tema, la planificación, el diseño, la toma de imágenes, que tuvieron como finalidad la construcción del relato autográfico, ayudaron en el proceso de autoconocimiento, pues dichas actividades funcionan como espejo ${ }^{6}$, convirtiéndose el acto fotográfico en una especie de instrumento de exploración de

\footnotetext{
${ }^{6}$ La acción del autorretrato tiene su génesis en la necesidad de mirarse. Lacan plantea que desde la primera infancia el niño demanda esta necesidad, habla de la celebración ante la fascinación del bebé al descubrir por primera vez su imagen en el espejo a esta etapa la designa
} 
ellos mismos. Suceso que en muchos casos sirve de herramienta de liberación. Al mirar la imagen que se ha tomado de sí mismo, de sus queridos, de sus espacios, se reconocen. Desde ese momento la relación que se establece con él mismo y con el mundo, cambia.

\subsection{El uso del espejo en el autorretrato como recurso pedagógico en jóvenes y adultos con NEE: Me veo te} veo en el espejo: Ya objetivada la construcción del sujeto el autorretrato se convierte en representación del yo tanto para sí mismo como para los otros yo. De esta forma se transfigura en herramienta de exaltación del sujeto y de autoevocación del Yo. El enfrentamiento con el espejo devuelve la certeza de que no existe diferencia entre lo que se mira y lo que se siente, ese reflejo representa la interacción continua entre el consciente y el inconsciente entre lo que sé que es y lo que siento que es, entre el yo y el otro yo. Para France Borel ${ }^{7}$ (1996:17): "Cualquier retrato, cualquier autorretrato despierta el enigma del doble. En la representación de éste o de aquél se teje un alquímico laberinto de identificaciones, de adueñamientos, de robo, de violaciones; la intimidad violentada. Buscarse en la propia imagen es buscarse en la mirada del otro".

En el apartado de autorretrato se buscaba principalmente el reconocimiento físico del cuerpo, su aceptación tal cual es y la satisfacción posterior por ese reconocimiento como efectivo a través de la autoexploración en el espejo, contribuyendo al desarrollo de un autocontepto real y positivo. De igual forma la participación como autores en la toma fotográfica les permitió ser constructores de su propia identidad ya que el espejo les ofreció una mirada directa y sin interferencias de terceros del su Yo.

En una primera fase se trabajó el autoconcepto y la autoestima a través del autorretrato, ya que un correcto conocimiento de la fisonomía y una adecuada valoración y aceptación de ésta, propicia sentimientos de seguridad en sí mismo y desarrolla la autonomía personal que redundará posteriormente en la toma de decisiones acertadas para la vida.

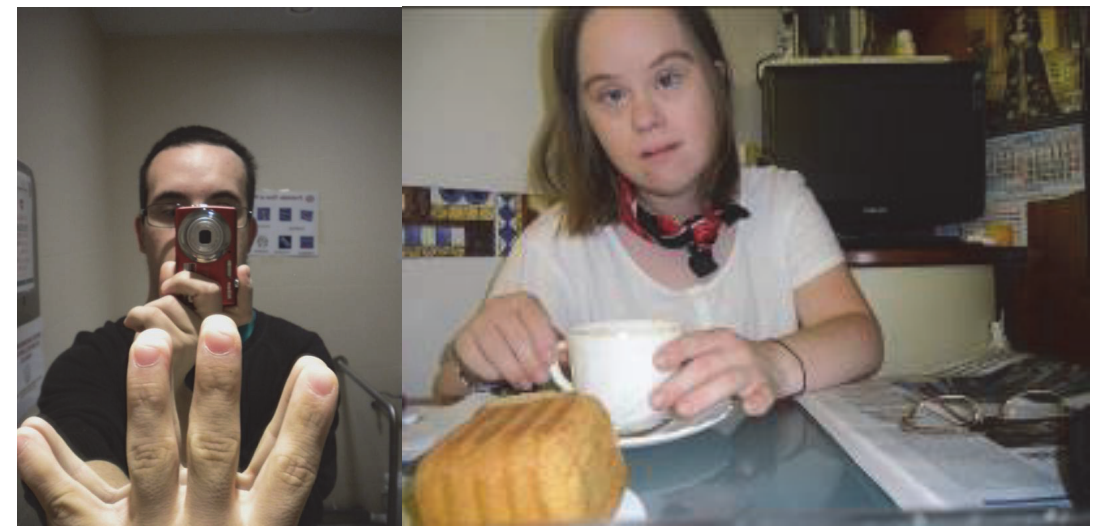

Figura 3: Autorretrato de Nicolás.

Figura 4: Autorretrato de María.

como le stade du miroir"; Sin embargo ya objetivada la construcción del sujeto el autorretrato se convierte en representación del yo tanto para sí mismo como para los otros yo. De esta forma se transfigura en herramienta de exaltación del sujeto y de autoevocación del yo. Alter ego como lo designó Plauto o "el otro" como lo nombraría Rimbaud o Borges. Foucault ${ }^{6}$ en el famoso estudio de las Meninas habla de la noción de doble visibilidad como representación de la representación.

${ }^{7}$ BOREL, F. Francis Bacon: las vísceras por rostro (Bacon. Portraits et autoportraits) en: KUNDERA, M; BOREL, F. BACON: retratos y autorretratos. 1996. P:17. 
"Relatos del YO": autobiografias visuales, foto de familia y autorretrato fotográfico como recursos de autoconocimiento en jóvenes y adultos con NEE

4.2. Objetos y espacios como representación del yo soy: En un primer ejercicio y a través de un taller de iluminación de estudio y de producto se les propuso realizarse autorretratos con un objeto que fuera de su preferencia. Sirvió para trabajar la empatía, la teoría de la mente, las predicciones y el punto de vista. Consideradas habilidades 'heterometacognitivas, ${ }^{8}$ al pedirles que colocaran a un compañero simulando que eran ellos mismos y de esta forma componer su propia pose y el encuadre elegido, para luego intercambiar roles.

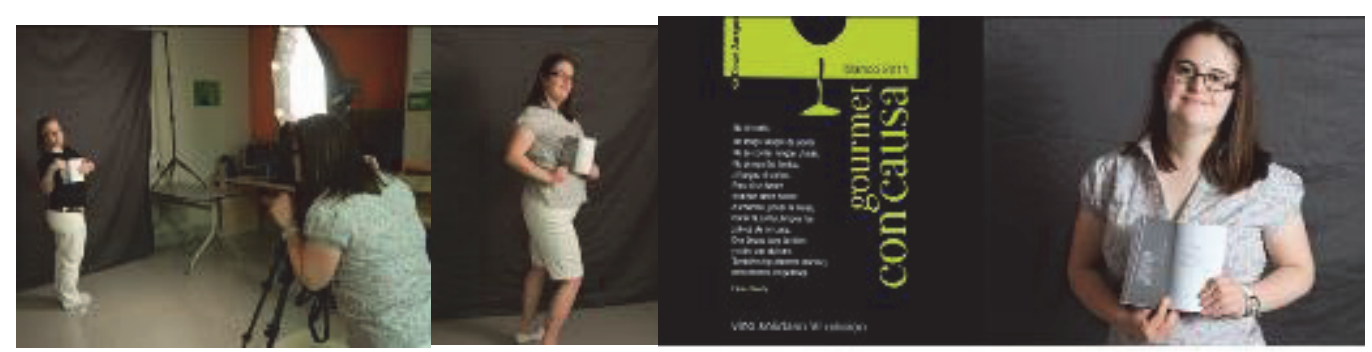

Figura 5: Mi objeto favorito.

Díptico de

Helena a partir del trabajo:

Ciudadanos de Peter de Carma

Casulá

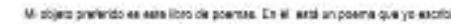

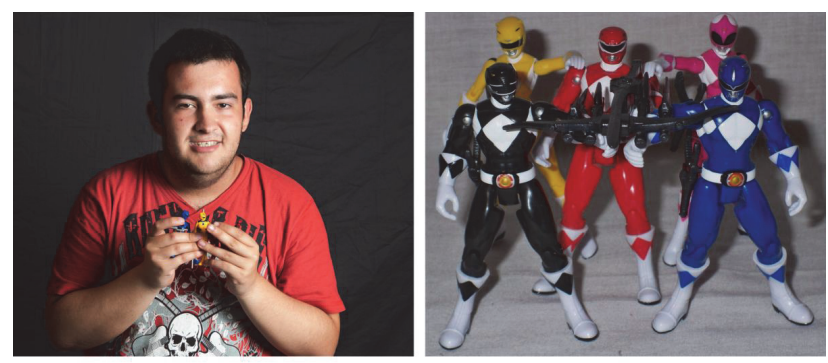

Los Power Rangers. Mi serie preferida desde peque.

Figura 6: Mi objeto favorito. Díptico de Daniel. a partir del trabajo: Ciudadanos de Peter de Carma Casulá

4.3. Imágenes familiares, imágenes mentales: la reconstrucción de la memoria a través de la foto de familia como enlace entre la ficción y la realidad:En esta parte del taller se trabajó con el álbum de familia. En el primer momento se utilizó el álbum familiar para narrar oralmente el relato vital de cada uno. Posteriormente se les pidió a los participantes que escogieran una foto que fuera realmente significativa para ellos, con la cual realizaron un pequeño relato escrito.

\footnotetext{
${ }^{8}$ Habilidades del sistema cognitivo que sirven para predecir lo que hace otro sistema cognitivo. En estas habilidades subyacen otras habilidades como: El reconocimiento facial de las emociones, las creencias de primer y segundo orden, el lenguaje social y la empatía.
} 


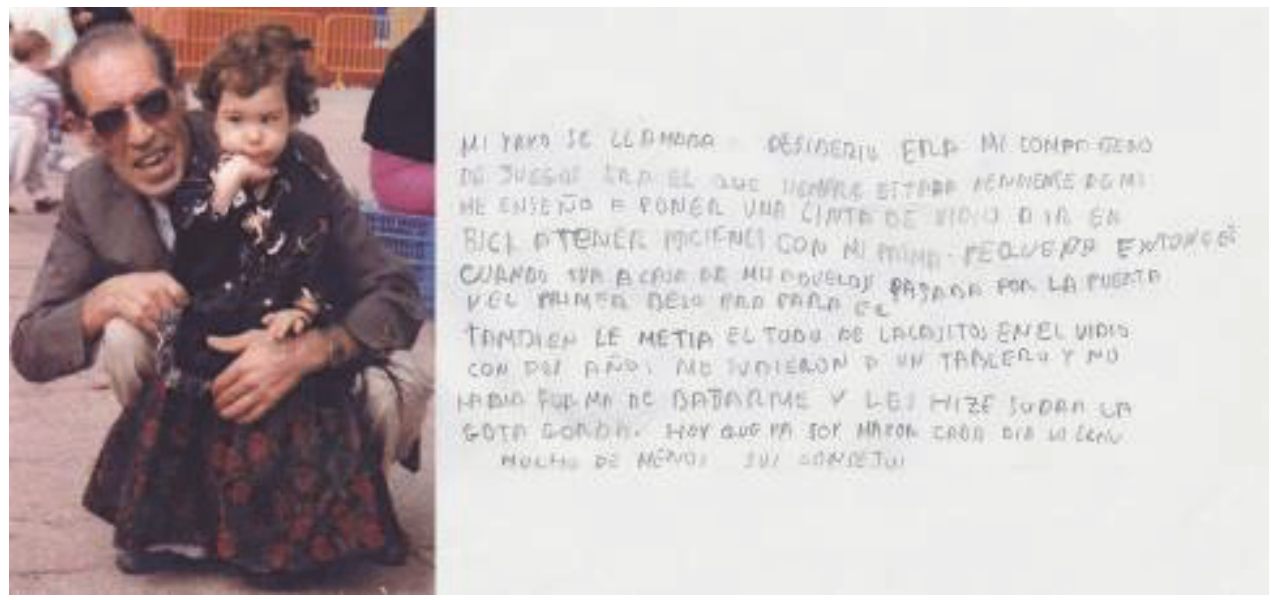

Figura 7: Foto de Familia de Vanesa.

\subsection{El relato visual autobiográfico como recurso de autoconocimiento: expreso con la palabra mi mundo} interno: La organización coherente de una o varias fotografías se considera un texto visual únicamente cuando se produce, estructura e interpreta desde un contexto socio-cultural determinado. Una fotografía aislada sin un lector y sin un contexto no significa absolutamente nada. Así, es viable que cada fotografía devenga en texto visual, en virtud de la conexión dialéctica que se establezca entre un fotógrafo emisor y un público lector. Acompañado muchas veces además de un título o un pie de foto que ayudan a anclar el mensaje de la imagen fotográfica y guiar al espectador en la lectura y que en muchos casos se convierte en un arma poderosísima que lleva a reinterpretar la fotografía. La imagen fotografía como unidad, como elemento unitario eterniza el suceso y lo preserva. Sin embargo cuando forma parte de un conjunto secuencial se activa su poder narrativo. Graf, C. $(2014)^{9}$ plantea que una fotografía “... es siempre fragmentaria, solamente una parte de la historia que muestra: Una fotografía puede mostrar, únicamente, la superficie, lo visible, lo concreto. Pero como parte de un todo, como una pequeña pieza de mosaico, revela una imagen mayor, de la dinámica invisible de la sociedad en la que vivimos".

En este apartado del taller se realizó una actividad introductoria para la creación de un relato fotográfico a partir de las imágenes de otros fotógrafos. Como primer momento de la actividad se escogió un portafolio de Jen Davis ${ }^{10}$ por su carácter autobiográfico documental, además del aspecto psicoemocional y de empatía. Esta narración o historia visual ${ }^{11}$ se construyó a través de una selección y ordenamiento de imágenes para lograr componer una historia. Se estableció una dinámica de preguntas y respuestas. Primero sobre la fotografía como unidad (el mensaje individual) y luego se realizaron a nivel grupal (el conjunto del mensaje): ¿Qué vemos?, ¿Qué sentimos cuando lo vemos?, ¿Quién es ella? Describirla físicamente y emocionalmente; ¿Qué le pasa? qué siente; ¿Dónde está? El lugar o los lugares donde se desenvuelve la historia. ¿Qué hace? y ¿Por qué lo hace? Entre todos se construyó la historia. En un ejercicio posterior se ejercitó la estructura de la historia cambiando el orden de las imágenes para descubrir que existen múltiples maneras de contar una historia.

En un ejercicio posterior se ejercitó la estructura de la historia, se les pidió que cambiaran el orden y tipo imágenes y que narraran la misma oralmente para descubrir que existen múltiples maneras de contarla. Durante

\footnotetext{
${ }^{9}$ GRAF, C. (2014). The birth of the photo essay: The first issues of LIFE and LOOK.

${ }^{10}$ Davis, Jen fotógrafa estadounidense que tiene un trabajo autobiográfico.

${ }^{11}$ Sobre el tema o trama: los temas o tramas son infinitos y deben estar relacionados con sus necesidades, preferiblemente escogidos por ellos y en cierta forma actúan (entre otras cosas) como motivadores al aprendizaje. Se utilizó en esta oportunidad para trabajar el autoconocimiento en chicos con NEE pero se puede usar entre otras cosas (lecto-escritura y comprensión lectora) como recurso para trabajar el acoso estudiantil ya que no solo tienen importancia los contenidos que sirven para desarrollar destrezas y habilidades "el hacer" en una u otra disciplina sino que se hace necesario temáticas que ayuden al desarrollo del "ser" al mismo tiempo que aprenden a hacer.
} 
"Relatos del YO": autobiografias visuales, foto de familia y autorretrato fotográfico como recursos de autoconocimiento en jóvenes y adultos con NEE

la segunda parte se realizó un relato con las imágenes de Franck Juery de forma grupal, con la finalidad de incentivar el cooperativismo y la identificación psicosocial de unos con otros.

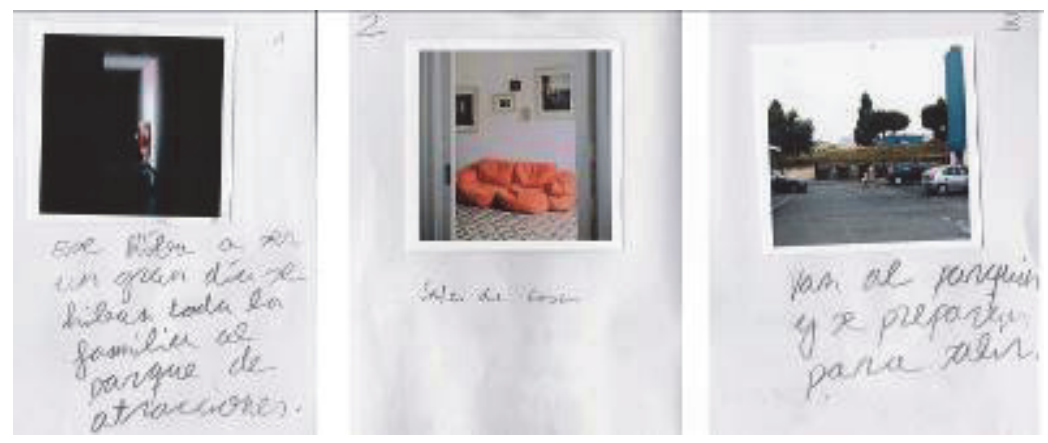

Figura 8: Relato visual a partir de las fotografias de Franck Juery 1/6 tripticos.

En la tercera fase de este apartado del relato visual, se expusieron dos actividades en las que se profundizó en el relato autobiográfico y en las que las imágenes fotográficas utilizadas para armarlo fueron autorretratos. Se utilizó el pie de foto que le otorgó sentido a todo el conjunto, pues se abordó como un cuento corto. En este apartado se buscó trabajar la creación de un texto completo. El segundo momento se refirió a la nivelación o reacomodo del conocimiento a través de la lectura oral de la producción escrita, momento que sirvió para realizar la autoevaluación y la coevaluación. Como primera actividad de esta fase se les pidió que realizaran un relato "descriptivo" sobre un tema relacionado con su espacio íntimo, que es su casa y familia (su hogar).
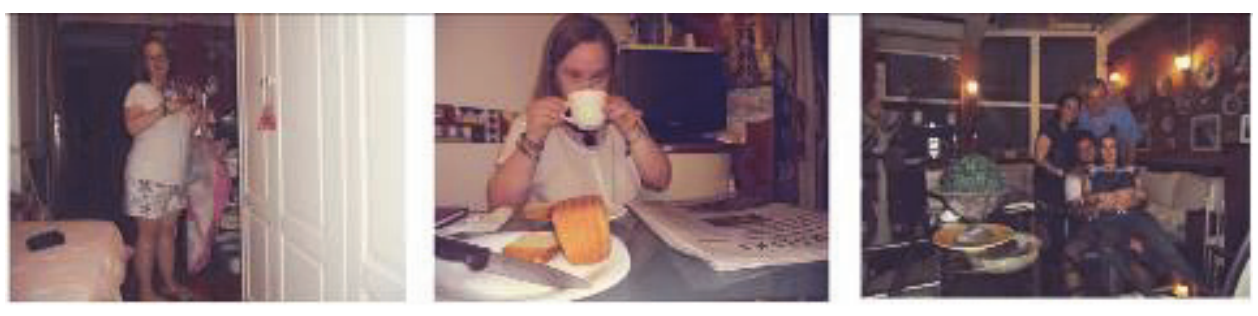

Micasa es precosa y mi habitadan ca mus grande Myo unn mi torsity. En mi cava hay Lna temazo.

Figura 9: Relato descriptivo de María en su casa (sus espacios).1/4 Trípticos

En la cuarta actividad de esta fase del apartado de relato autobiográfico se les propuso a los participantes narrar un día completo de sus vidas a través del autorretrato. Se les pidió que organizaran una narración a través de sus fotografías con una estructura secuencial temporal. Como segundo momento se les pidió que le colocaran el título y el pie de foto.

\subsection{La ficción como recurso para la expresión del Yo. El relato visual y el autorretrato como recursos de} ficción: En el autorretrato la persona es él mismo pero representado como otro, un duplicado con una puesta en escena. A diferencia del ensayo el relato fotográfico no siente el deber de construirse sobre bases de verdad, sino que puede libremente a través de la construcción imaginaria plantear ficciones para expresar situaciones que "existen" o han existido de una u otra forma como consecuencia de su experiencia vital. 
En la primera parte de este apartado los participantes observaron su fotografía y conversaron sobre las características que más les gustaron, se miraron al espejo. Se le propuso la intervención de la fotografía, estimulando a resaltar aquellas características que más le gustan de sí mismos; para ello se les propuso dibujar el cuerpo de un superhéroe y pensar en los poderes que les gustaría tener y para qué los usarían. De esta forma crearon un personaje de ficción a partir de la fotografía de autorretrato. En la segunda parte realizaron un relato de ficción a partir de la observación y análisis del trabajo la Suite vénitienne de Sophie Call.
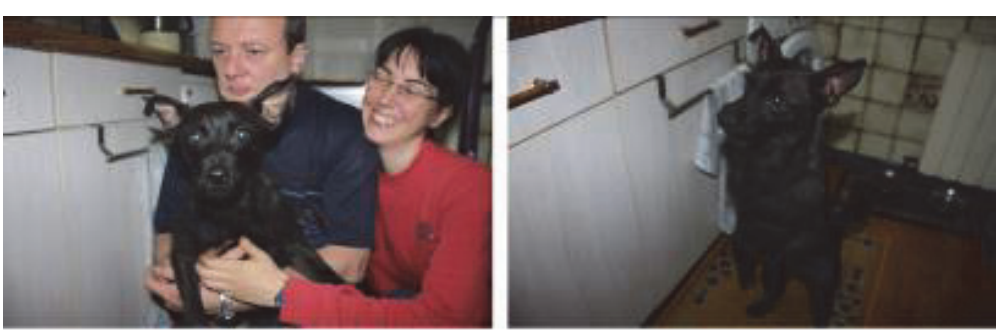

Figura 10: Relato fantástico de Vanesa basado en el trabajo de Shopie Call.3/5 Dípticos
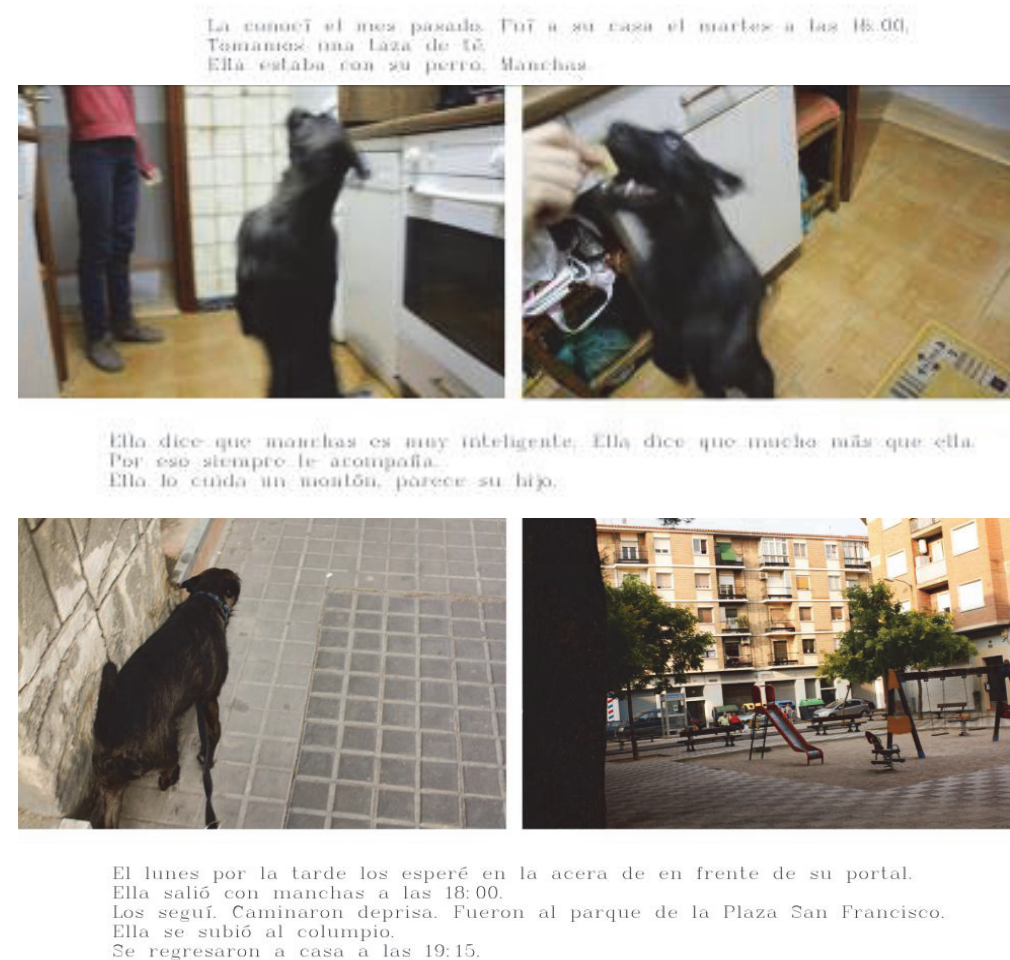

\subsection{Resultados del test de autoestima.}

Metodología: Contrastes de medias entre los participantes pre y pos intervención.

Instrumento: Escala de Autoestima de Rosenberg (Rosenberg, 1965).

Resultados: como se puede observar se encuentran efectos significativos en la medida de autoestima en los dos contrastes independientemente del sexo, síndrome o discapacidad. En el grupo de sexo femenino se observó mayor incremento de la autoestima después de la intervención. Por otro lado también se identificó una mejoría notable en los participantes con Trastornos generalizados del desarrollo.

Efectos sobre otras variables: se observó notables mejoras en la ansiedad, las habilidades sociales y la solución de problemas. 
"Relatos del YO": autobiografias visuales, foto de familia y autorretrato fotográfico como recursos de autoconocimiento en jóvenes y adultos con NEE

Tanto en las Tablas 4 y 5 y como en las Figuras 4 y 5 se han graficado los rangos pre-intervención y postintervención, los cuales muestran una tendencia creciente en la medida de la autoestima, pasando en la muestra femenina de una autoestima baja con 24 puntos a una autoestima elevada con 33,5 puntos, respectivamente. En la muestra masculina de 23,33 puntos a 32,6 puntos.

Tabla: 2. Rango, puntuaciones medias muestra femenina.

\begin{tabular}{|c|c|c|c|c|}
\hline \multirow{2}{*}{$\begin{array}{c}\text { SEXO } \\
\text { FEMENINO }\end{array}$} & \multirow[b]{2}{*}{ SINDROME } & \multicolumn{2}{|c|}{ RANGO } & \multirow[b]{2}{*}{ MEDIA } \\
\hline & & $\begin{array}{l}\text { Pre- } \\
\text { intervención }\end{array}$ & $\begin{array}{l}\text { Post- } \\
\text { intervención }\end{array}$ & \\
\hline & Autismo & 20 & 32 & 26 \\
\hline & $\begin{array}{l}\text { Inteligencia límite y Trastorno } \\
\text { de la afectividad }\end{array}$ & 18 & 29 & 23,5 \\
\hline & Retraso mental ligero & 29 & 40 & 34,5 \\
\hline & Retraso mental ligero & 26 & 32 & 29 \\
\hline & Retraso mental ligero & 18 & 32 & 25 \\
\hline & Síndrome de Down & 32 & 40 & 36 \\
\hline & Síndrome de Down & 29 & 32 & 30,5 \\
\hline & $\begin{array}{l}\text { Discapacidad del sist. } \\
\text { neuromuscular }\end{array}$ & 20 & 29 & 24,5 \\
\hline & MEDIA & 24 & 33,25 & \\
\hline
\end{tabular}

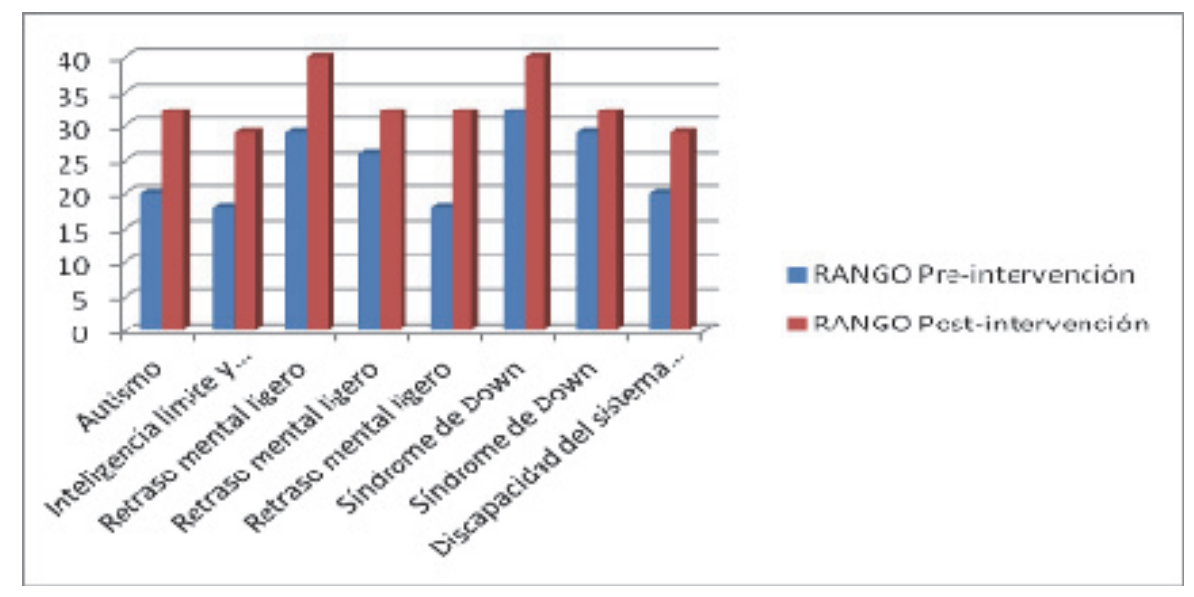

Fig: 11. Gráfico de muestra femenina pre-intervención y post-intervención

Tabla: 3. Rango, puntuaciones medias muestra Masculina.

\begin{tabular}{|l|l|c|c|c|}
\hline \multirow{2}{*}{$\begin{array}{c}\text { SEXO } \\
\text { MASCULLINO }\end{array}$} & \multicolumn{1}{|c|}{ RINDROME } & $\begin{array}{l}\text { Pre- } \\
\text { intervención }\end{array}$ & $\begin{array}{l}\text { Post- } \\
\text { intervención }\end{array}$ & MEDIA \\
\hline \multirow{5}{*}{} & Prader Willy & 26 & 40 & 33 \\
\cline { 2 - 5 } & Asperger & 20 & 36 & 28 \\
\cline { 2 - 5 } & $\begin{array}{l}\text { Discapacidad intelectual por } \\
\text { tumor cerebral }\end{array}$ & 32 & 36 & 34 \\
\cline { 2 - 5 } & Retraso mental ligero & 18 & 29 & 23,5 \\
\cline { 2 - 5 } & Retraso mental moderado & 18 & 26 & 22 \\
\cline { 2 - 5 } & Síndrome de Down & 26 & 29 & 27,5 \\
\hline
\end{tabular}




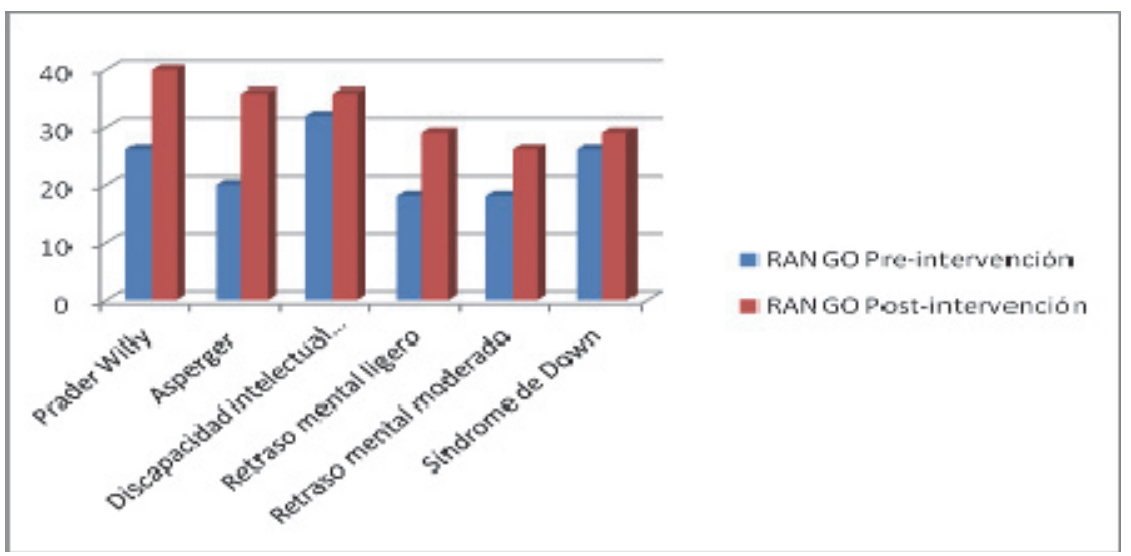

Fig. 12. Gráfico de muestra masculina pre-intervención y post-intervención.

La siguiente tabla muestra la comparación entre las muestras pre intervención y post intervención, tanto del test de autoestima (cuantitativas) como del instrumento en forma de mapa mental del proyecto de vida (cualitativa) de uno de los participantes del taller. En esta figura se observa que el cambio es similar tanto en las medidas de las muestras del test como en la observación directa del instrumento. Se observa que en este primer texto se describe mostrando un auoconcepto físico ajustado a la realidad. También dice que es presumida. Tímida, pero a pesar de ser tímida también soy maja (aclara). Cuando se lee el último texto se observa un cambio significativo. La descripción que ella hace de sí misma abunda ahora en adjetivos calificativos mostrándo además de un autoconcepto apropiado a ella una sensación de una autoestima más elevada. Además tiene un deseo de futuro: ser independiente. Además un resultado similar se observa en la graficación del test de autoestima que se le aplicó, la barra azul señala el momento en que redacto el primer texto y la barra roja señala el segundo texto.

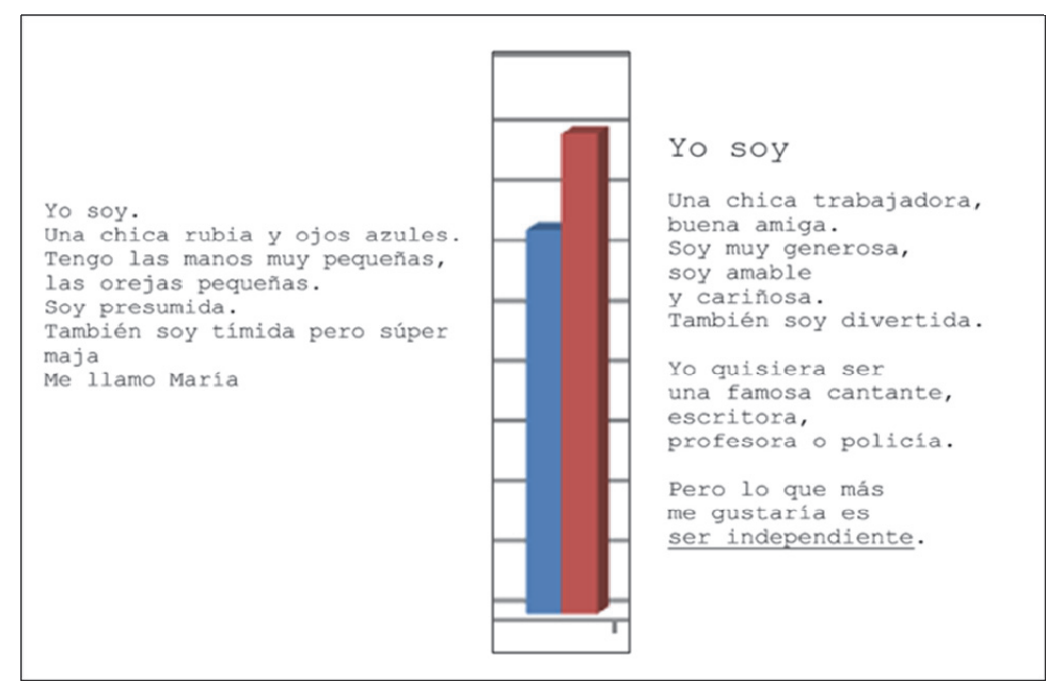

Fig. 13. Gráfico comparativo de muestra del test y estracto de mapa de proyecto de vida. Pre y post intervención.

La siguiente tabla se refiere al comportamiento de los niveles de autoestima a lo largo del tiempo de duración de la intervención. Se puede observar que en los participantes de sexo femenino el aumento de la autoestima fue mayor. 
"Relatos del YO": autobiografías visuales, foto de familia y autorretrato fotográfico como recursos de autoconocimiento en jóvenes y adultos con NEE

Tabla: 4. Total: Rango, puntuaciones medias, desviación

\begin{tabular}{|l|l|c|c|c|c|c|}
\hline $\begin{array}{l}\text { TAMAÑO DE LA } \\
\text { MUESTRA: 14 }\end{array}$ & SEXO & N & \multicolumn{2}{|c|}{ RANGO } & MEDIA & DS \\
\hline & & & MÍNIMO & MÁXIMO & & \\
\hline & FEMENINO & 8 & 18 & 40 & 33,25 & 4.74 \\
\hline & MASCULINO & 6 & 18 & 32 & 32,7 & 5.00 \\
\hline & TOTAL & 14 & 18 & 40 & 32,97 & 5.91 \\
\hline
\end{tabular}

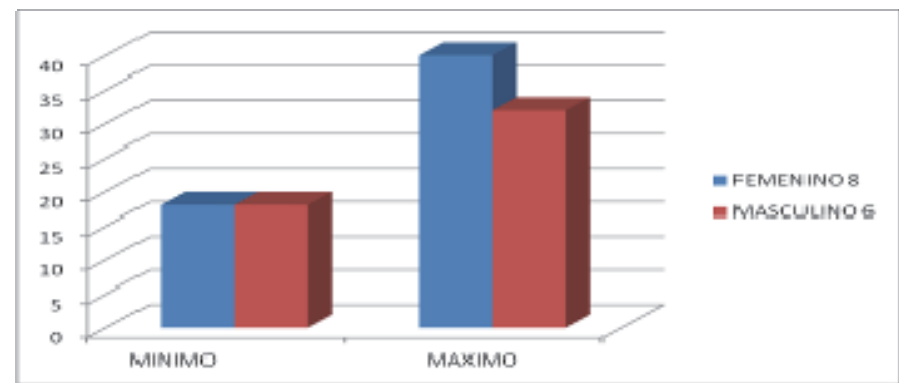

Fig. 14. Gráfico de muestra total. Rango mínimo y máximo.

\section{Conclusiones}

A través de los datos proporcionados durante la investigación y los resultados del estudio, se puede afirmar que de forma general este taller contribuye a aumentar los niveles de autoestima de forma general en jóvenes y adultos con Necesidades Educativas Especiales. El resultado donde se observa un mayor aumento de la autoestima en la muestra femenina se puede explicar a través del concepto de la máscara y las representaciones que la mujer hace para ocultar y proteger su integridad psicológica, su verdadero Yo. En el momento en que a la mujer se le dice que puede liberarse de los estereotipos, encontrarse con su Yo legítimo, que puede decir o hacer lo que quiera y como quiera y que además nadie la juzgará, en ese momento la persona se libera. Esto hace que se active el proceso de construcción y reconstrucción de la identidad de la persona de manera sana, autentica y sincera consigo misma. Además a través de este tipo de intervencion donde la fotografia autobiográfica juega un papel protagonista, se puede confirmar que el concepto de social de Mujer es interseccional y se extiende a todo tipo de raza, etnia, capacidad (dis), síndrome, nivel socioeconómico u origen de nacimiento tal cual lo planteara Crenshaw, K. $(1995)^{12}$.

De igual forma la fotografía en su faceta de autorretrato sirve de método proyectivo y de construcción y reconstrucción de la identidad propia. Puesto que esta pasa de ser un objeto pasivo avocado a la contemplación para convertirse en uno activo, ya que esta es activamente posada, hablada, narrada, construida y posteriormente reconstruida cuando los participantes estructuran un mensaje a través de la organización de un texto visual y/o escrito. De esta forma la fotografía se convierte en instrumento con el que se crean nuevas y múltiples narrativas representadas por y a través de la construcción y/o reconstrucción de una historia personal en que en algunos casos también dialogan varias fotografías. Este fenómeno o mecanismo fotoproyectivo que hace que el observador-participante construya un significado para luego darse cuenta de su inestabilidad característica, al ver como su significado cambia rápidamente de acuerdo al que la mira y la lee y su contexto,

\footnotetext{
${ }^{12}$ CRENSHAW, Kimberlé (1995): Mapping the Margins: Interseccionality, Identity Polítics and violence Againts Women of Color en K. Crenshaw; N. Cotanda; C. Peller; K. Thomas (eds.) Critical Race Theory. The key writings that formed the movement. p. 357-383. New York: The New Press.
} 
contribuye a que los participantes puedan darse cuenta que la interpretación de cada uno es personal, selectiva e inconsciente.

El taller además contribuye tanto a activar procesos de alto nivel relacionados con el acto de leer o escribir, como a ayudar al desarrollo de los diferentes tipos de inteligencias. Concepto basado en la propuesta de Gardner sobre las investigaciones en el que plantea que no existe solo una inteligencia, sino que son ocho.

Es así como en este caso la utilización de la fotografía, el autorretrato fotográfico así como las autobiografías visuales en entornos educativos, ejercitan además de la lingüística-verbal por todo lo expresado anteriormente; la inteligencia naturalista, al establecer relaciones y analogías entre elementos, así como la observación, la identificación, la clasificación y la construcción de analogías; la inteligencia intrapersonal e interpersonal, al reconocerse y reconocer a los otros y al expresar lo que piensa y lo que siente en público; la visual-espacial, al tratar de otorgarle sentido a través de la organización espacial de las imágenes y la lectura de las fotografías, creando imágenes mentales, percibiendo detalles visuales; y la lógico-matemática, que implica el poder identificar objetos, formular y verificar hipótesis, así como los razonamientos inductivo y deductivo.

En cuanto al apartado de álbum de familia se observó como la fotografía es un medio privilegiado de narración, mucho más si se incorpora la memoria a través de la foto de familia y el álbum familiar, puesto que estos dos involucran a la persona y su presencia directamente con lo narrado. En ellos la memoria funciona como recurso de evocación; como retorno al pasado, a lo que fue y ya no es; como rememoración de la ausencia, de los ausentes, con el inquietud de la pérdida; la foto de familia devuelve la voz a lo que ya no quiere ser nombrado; es también memoria fragmentada que posibilita el llenado de huecos a través de la reinvención especulada de lo real; Sin embargo esta capacidad del álbum familiar de preservar la memoria se une a la característica inestable de ésta. Los hechos que una vez fueron ya no son y es aquí cuando la historia familiar se reescribe constantemente una y otra vez, por uno o varios miembros de la familia. ${ }^{13}$ El relato real se convierte en juego que sirve a la ficción, yo cuento de mí y mi familia una y otra vez para mí y los otros. El álbum familiar se transforma en herramienta para la construcción y representación de las ficciones familiares. ${ }^{14}$ Asimismo, se convierte en herramienta contra el olvido. Sirve además como reflexión de la identidad personal y vehículo para la resignificación de las experiencias vitales. ${ }^{15}$

La fotografía entonces ya no solo es autorretrato sino que se convierte en "espejo con memoria". Este tipo de fotografías hace visible la característica evocadora de la imagen fotográfica, y su capacidad de mimetismo y adaptabilidad $^{16}$.

En cuanto al apartado de el relato visual autobiográfico como recurso de autoconocimiento, se puede afirmar sin ninguna duda que en los diferentes ejercicios realizados se llevaron a cabo los procesos de construcción de un texto visual, pues en ellos se observaron tanto el proceso interactivo, el proceso inferencia, como el de connotación. Se puede decir entonces que la escritura es principalmente un proceso de construcción de sentido ya sea esta a través de la fotografía o imagen gráfica, de la literatura, de la música o cualquier otra disciplina

\footnotetext{
${ }^{13}$ Así Deleuze (1995:70) señala: "El pasado de la memoria es doblemente relativo: relativo al presente que ha sido y relativo al presente de la rememoración en relación a la cual ahora es pasado; por lo que el pasado no representa solamente algo que ha sido sino algo que vuelve a ser..."

${ }^{14}$ Bourdieu, (2003:334) en un arte medio, "la percepción fotográfica nos conduce de la presencia de la ausencia, de la irrealidad a la realidad, $y$ viceversa".

${ }^{15}$ Como bien lo plantea Puerta, G. (2013:84): “Cuando nos adentramos en las páginas del álbum de fotografias estamos vislumbrando el pasado desde el presente. Al recordar, al rememorar, al detenernos a pensar por un instante en el paso del tiempo o en el significado que le atribuimos a ciertos momentos de nuestra vida, a los cambios que hemos experimentado, y preguntarnos que ha permanecido y que se ha transformado."

${ }^{16}$ Como lo diria Fontcuberta: (1997: 58)"Fotografiamos para recordar aquello que hemos fotografiado, para salvaguardar la experiencia de la precaria fiabilidad de la memoria ¿O no?"
} 
"Relatos del YO": autobiografias visuales, foto de familia y autorretrato fotográfico como recursos de autoconocimiento en jóvenes y adultos con NEE

que se utilice. Una misma selección de imágenes gracias a su organización puede expresar multitud de mensajes.

Es como de esta forma se puede a través de la utilización de imágenes fotográficas activar procesos de connotación, significación y comprensión, además de aprender un "procedimiento" de "construcción" de la lectura o escritura, partiendo del tema y la trama. También se puede pensar la imagen fotográfica como una palabra. Un signo gráfico que contiene en sí mismo un significado, a modo del sistema de escritura chino el cual se compone de miles de signos gráficos. De esta forma se estará trabajando la lectura - escritura de forma holística. No importa la lengua que se use si realmente cuando lo que realmente importa es el desarrollo de la comunicación y de los procesos de alto nivel. Escribir con imágenes fotográficas un relato visual para luego "leerlo" en voz alta. Trabajar los procesos de "alto nivel" sin importar el código lingüístico o la lengua para después escribir un pequeño texto u oración como un pie de foto para terminar de anclar el mensaje.

Entonces, el autorretrato fotográfico, los relatos visuales y la foto de familia ayudan a sumergir al individuo en su mundo interno y subjetivo, contribuyendo a darle forma a su identidad a través de la construcción y reconstrucción visual acerca de su realidad vital. El uso de la imagen fotográfica se convierte en herramienta eficaz para favorecer la adecuada valoración personal, el autoconocimiento y la autoestima. Favorece la intervención de los diferentes aspectos del individuo, principalmente los aspectos afectivos y emocionales, personales, de su historia familiar así como de su entorno social, facilitando la expresión y el desarrollo personal en jóvenes y adultos con necesidades educativas especiales. Finalmente, se puede concluir que la conexión entre la fotografía y la educación como herramientas de transformación social es factible.

\section{Referencias}

ANSÓN, A. Retrato (fotográfico) de lo íntimo. En ANSÓN, A. (dir.) (2003): Los mil retratos de la imagen y uno más. Huesca: Diputación de Huesca, pp. 40-41.

ANZIEU, D. (1993). La piel, la madre y el espejo en los cuadros de Francis Bacon en El cuerpo de la obra. Siglo XXI. México.

CRENSHAW, Kimberlé (1995): Mapping the Margins: Interseccionality, Identity Polítics and violence Againts Women of Color en K. Crenshaw; N. Cotanda; C. Peller; K. Thomas (eds.) Critical Race Theory. The key writings that formed the movement. p. 357-383. New York: The New Press.

BACHELARD, G. (2012). Poética de la ensoñación. Fondo de cultura económica de España.

BALTRUŠAITIS, J. (1978). El espejo: ensayo sobre una leyenda científica: revelaciones, ciencia ficción y falacias; traducción Francisco J. Arellano. Madrid Miraguano Polifemo. 1988.

BANDURA, A. (1987). Pensamiento y acción: Fundamentos sociales. Barcelona: Martínez Roca.

BEANE, J. A. Y LIPKA, R. P. (1980). Self concept and self-esteem: A construct differentiation. Child Study Journal 10: 1-6.

BERGER, P. (1973) La identidad como problema en la sociología del conocimiento. En G. Remmling (compilador). FCE, México. 1982.

BERGSON, H. (2006). Materia y memoria Ensayo sobre la relación del cuerpo con el espiritu. CACTUS.

BOURDIEU, P. (2003). La definición social de la fotografía. La fotografia un arte intermedio. Madrid. Editorial Gustavo Gilli.

CORREA, C. (2004). Currículo Dialógico Sistémico e Interdisciplinario. Editorial Transversales Magisterio. Bogotá, Colombia.

DELEUZE, G.(1995). Proust y los signos, Ed. Taunus, Madrid. 
DELORS, J. (1996). La educación encierra un tesoro. Capítulo 4, Los cuatro pilares de la educación. México: UNESCO. El siglo XXI. (Pp. 89-103). [En línea], Disponible en: http://www.unesco.org/education/pdf/DELORS_S.PDF [Consulta 2016, noviembre 09]

DUBOIS, P. (1994): El acto fotográfico. De la recepción a la representación. Barcelona: Paidós Comunicación. FONTCUBERTA, J. (1997): El beso de Judas. Barcelona: Gustavo Gili, pp. 53-71.

FOUCAULT, M. (1992). Las palabras y las cosas: una arqueología de las ciencias humanas. Título original: Mots et les Choses, México, Siglo xxi, 2001

FREUND, Gisèle. 2004 [1974]. La fotografía como documento social. Editorial Gustavo Gili S.A. Barcelona, España.

FRITH, U. Y HAPPÉ, F. (1999) "Theory of mind and self-consciousness: What is it like to be autistic?". Mind \& Language, Vol $14 N^{o} 1$. Disponible en: http://onlinelibrary.wiley.com/doi/10.1111/1468-0017.00100/abstract [Consulta 2016, abril 25].

GARDNER, H. (1987). La teoría de las inteligencias múltiples, Fondo de Cultura, México.

GÁMEZ, G. (1998). Todos somos creativos. Barcelona, Urano. 1998.

GÓMEZ, JM; ROYO P; SERRANO, C (2009) Fundamentos psicopedagógicos de la atención a la diversidad. La atención educativa a los alumnos con discapacidad intelectual. Colección Textos Docentes. EUCC.

GONZÁLEZ FLORES, L. (2005). Fotografia y pintura ¿dos medios diferentes? Barcelona: Gustavo Gili.

GRAF, C. (2014). The birth of the photo essay: The first issues of LIFE and LOOK. Disponible en: http://www.academia.edu/7916898/The_birth_of_the_photo_essay_The_first_issues_of_LIFE_and_LOOK [consulta 201529 octubre]

GUASCH, A. (2011). Arte y archivo, 1920-2010: genealogías, tipologías y discontinuidades, Akal, Madrid.

HABERMAS, J. (1985). Conciencia moral y acción comunicativa. Barcelona, Península.

HARTER, SUSAN (1997), ["Desarrollo de la personalidad y de la identidad" y "Formación de la identidad"] "Self and identity development" y "Identity Formation", en S. Shirley Feldman and Glen R. Elliott (eds.), At the threshold. The developing adolescent, EUA, Harvard university Press, pp. 352-368, 375-387.

HERNÁNDEZ, A. (2005). "El método biográfico en investigación social: potencialidades y limitaciones de las fuentes orales y los documentos personales". Asclepio. Vol 57. No 1. Disponible en: http://asclepio.revistas.csic.es/index.php/asclepio/article/viewArticle/32 abstract [Consulta 2017, abril 20].

JEAN, I; BARBEN. ( 2002 ). Psicología del Niño. ( $16^{\text {a }}$.Ed.). Madrid- España.

LACAN, J.(2013) La instancia de la letra en el inconsciente o la razón desde Freud p. 4841.a edición en Editorial Biblioteca Nueva, S. L., 2013.

LACAN, J. (1971). El estadio del espejo como formador de la función del yo (je) tal como se nos revela en la experiencia psicoanalítica. Escritos 1. Mexico. Siglo XXI. 2009. Disponible en: https://arditiesp.files.wordpress.com/2012/10/lacan_estadio_del_espejo.pdf [Consulta 2015, junio abril 20].

LACAN, J (1953). "SIR, lo simbólico, lo imaginario y lo real”. 1953. Conferencia del 8 de Julio de 1953. Disponible en sitio web: http://webcache.googleusercontent.com/search?q=cache:sLgjASB1f5oJ:www.lacanterafreudiana.com.ar/2.5.1.4 \%2520\%2520\%2520LO $\% 2520$ SIMB, \%2520LO \%2520IMAG\%2520Y\%2520LO \%2520REAL, \%25201953..pdf $+\& \mathrm{~cd}=1 \& \mathrm{hl}=\mathrm{es} \& \mathrm{ct}=\mathrm{clnk} \& \mathrm{gl}=\mathrm{es}$ [Consulta 2016, agosto 20]

LEJEUNE, P. (1975). Le pacte autobiographique, traducido al español, El pacto autobiográfico y otros estudios (1994). Madrid: Megazul- Endimión.

LÓPEZ-BARAJAS; ZAYAS, E. (1996). Las historias de vida y la investigación biográfica. Fundamentos y metodología. UNED.

MAYOR, J., SUENGAS, A.; GONZÁLEZ-MARQUÉS, J. (1993). Estrategias Metacognitivas. Aprender a aprender y aprender a pensar. Ed. Síntesis Psicología. Madrid. 
"Relatos del YO": autobiografías visuales, foto de familia y autorretrato fotográfico como recursos de autoconocimiento en jóvenes y adultos con NEE

MIRAUX, J. (2005). La autobiografia: Las escrituras del yo. Buenos Aires: Nueva Visión.

METZ, C., \& ELÍAS, J. (2001). El significante imaginario : Psicoanálisis y cine. Barcelona: Paidós.

PUERTA, G. (2013). (La construcción de la infancia en el álbum familiar) en: Álbum de Familia. VISIONA.

RANCIÈRE, J. (2005) [2001], "La ficción documental: Marker y la ficción de la memoria". En J. Rancière, $L a$ fábula cinematográfica. Reflexiones sobre la ficción en el cine. Barcelona, Paidós.

RAPOSO, G. "Narrativas de la imagen: Memoria, relato y fotografía". Revista Chilena de Antropología Visual número 13 - Santiago, junio 2009 - P: 79/103 pp.

RIBALTA, J. (2004). Efecto real: Debates posmodernos sobre fotografia. Barcelona: Gustavo Gili.

RIBÉS, C. (2002). "La ausencia del objeto". Ciclo de conferencias Iconoclastia, Lacan y psicoanálisis. UNIA.

RIVIÈRE, A. Y COLL, C. (1985.) "Individuación e interacción en el período sensomotor: Apuntes sobre la construcción genética del sujeto y el objeto social". XXime Journées d'etude de l'APSLE Lisboa.

RODRÍGUEZ, F. (2000). "El género autobiográfico y la construcción del sujeto autorreferencial". Filología y Lingüistica XXVI (2), 9-24.

SONTAG, S. (2003). Sobre la fotografia. Madrid. Alfaguara.

TAYLOR, C. (1996). Fuentes del yo: La construcción de la identidad moderna. Barcelona: Paidos.

VERA, B. (2000)"El arte: factor determinante en el proceso educativo". Educar: Revista de Educación. México. No 15 p: 56-65.

VIGOTSKY, L. (2012). La imaginación y el arte en la infancia. (11 ${ }^{\mathrm{a}}$ edic). Madrid: Akal.

VIGOTZKY, L. (1995) Pensamiento y Lenguaje. Barcelona: Ediciones Paidós.

ZUNZUNEGUI, S. (1989). Pensar la imagen. Madrid: Catedra : Universidad del Pais Vasco. 